\title{
LONG-TERM VARIATIONS IN THE CENTROID HEIGHT OF THE ATMOSPHERIC SODIUM LAYER
}

\author{
Barclay Robert Clemesha, Paulo Prado Batista and Dale Martin Simonich \\ Instituto Nacional de Pesquisas Espaciais, CP 515, São José dos Campos, 12245-970 SP, Brazil
}

\begin{abstract}
In earlier studies, an analysis of the long-term variation in the centroid height of the atmospheric sodium layer suggested the existence of a secular decrease in the height of the layer. The analysis of lidar data obtained between 1972 and 1994 indicated a fall of $740 \mathrm{~m}$ over this 22 year time period. A possible solar cycle variation with an amplitude of $170 \mathrm{~m}$ was also detected, although with low statistical significance. A new analysis, in which care was taken to exclude days in which sporadic sodium layers were present, and including measurements made up to the end of 2001, shows that the linear trend has not continued. The fall in centroid height observed in the early data is found to be compensated by a higher values observed since 1988, and the overall linear trend for 1972 to the end of 2001 is now only $93 \pm 53$ metres/decade. This new result strongly suggests that the previously detected trend was not a consequence of long-term global cooling of the upper atmosphere. $\mathcal{C} 2003$ COSPAR. Published by Elsevier Ltd. All rights reserved.
\end{abstract}

\section{INTRODUCTION}

It is believed that the observed long-term increase in the concentration of greenhouse gases in the atmosphere should lead to atmospheric cooling at heights above the tropopause. A number of workers have attempted to model such an effect. These studies have generally aimed at the so-called "doubled $\mathrm{CO}_{2}$ scenario". One of the earliest of such studies was that of Roble and Dickinson (1989). For a doubling in the concentration of atmospheric $\mathrm{CO}_{2} \mathrm{Ro}-$ ble and Dickinson (1989) found a temperature decrease of $15 \mathrm{~K}$ at $50 \mathrm{~km}$ and more than $50 \mathrm{~K}$ at $400 \mathrm{~km}$.

In recent years a number of workers have developed more detailed atmospheric models allowing predictions to be made for the effect of increased greenhouse gas concentrations. Brasseur et al. (1990) presented a chemicaldynamical-radiative model that includes Rossby wave absorption and gravity wave breaking. For the doubled $\mathrm{CO}_{2}$ scenario they found maximum cooling at around $50 \mathrm{~km}$, with temperature changes between $-16 \mathrm{~K}$ at the winter pole to $8 \mathrm{~K}$ at the equator. This model gave a small increase in temperature below $20 \mathrm{~km}$, and zero effect at $70 \mathrm{~km}$. Akmaev and Fomichev (2000) have modeled the effects of the increase in $\mathrm{CO}_{2}$ known to have occurred over the past $3-4$ decades. For a change in $\mathrm{CO}_{2}$ concentration from 331 to $360 \mathrm{ppm}$, they found temperature changes going from 0 at $20 \mathrm{~km}$ to about $-10 \mathrm{~K}$ at $180 \mathrm{~km}$. The trend did not increase monotonically with height, and was close to zero at $120 \mathrm{~km}$. The trend modeled by Akmaev and Fomichev (2000) provides a convenient basis for comparison with measured trends. Portmann et al. (1995) studied the effects of including dynamical feedbacks in the Garcia and Solomon (1985) two-dimensional model. They found that such feedbacks have a major effect, especially at the summer pole, where the doubled- $\mathrm{CO}_{2}$ scenario produced net heating of about $14 \mathrm{~K}$ without feedbacks, but cooling of around $6 \mathrm{~K}$ with. Portmann et al. obtained typical trends, with dynamical feedbacks included, of $0 \mathrm{~K}$ at $20 \mathrm{~km}$ to $-25 \mathrm{~K}$ at $110 \mathrm{~km}$.

A number of workers have attempted to detect a long-term trend in experimental data pertaining to the mesosphere and lower thermosphere. Rocket measurements, for example, made over a period of around 30 years, have been analyzed by various groups (Kokin and Lysenko, 1994; Keckhut et al., 1999; Dunkerton et al.,1998; Lubken et al., 2000). Most of these analyses have shown negative trends, but the reliability of the measurements is questionable in view of calibration problems and technical changes that occurred within the time series. Other studies have been based on satellite radiometer measurements (Aikin et al., 1991), lidar (Aikin ct al., 1991; Keckhut et al., 
1995; 2001), the height of radio wave reflection (Bremer, 1992; Jarvis, 1998; Taubenheim,1997) and airglow measurements of rotational temperature (Golitsyn et al., 1996; Bittner et al., 2000). Most, although not all, of these studies have shown decreasing temperatures in the mesosphere and thermosphere.

Ten years ago we published a paper (Clemesha et al., 1992) which demonstrated the existence of a statistically significant long term trend in the centroid height of the atmospheric sodium layer measured by a sodium lidar operating at São José dos Campos $\left(46^{\circ} \mathrm{W}, 23^{\circ} \mathrm{S}\right)$. We pointed out that the decrease in the centroid height, observed from 1972 to 1986 could be interpreted as evidence for a decrease in the height of isobaric levels in the atmosphere, resulting from global cooling. In a later paper (Clemesha et al., 1997) we analyzed an extended data set, going up to 1994. The new analysis continued to show a negative trend (although somewhat reduced in magnitude) together with a possible solar cycle variation. This study showed, however, that the decrease in height of the centroid did not result from a simple lowering of the layer, but involved a change in its shape, which we suggested might be the result of a change in the phase of the solar diurnal tide. In the present report we analyze data up to 2001 , thus covering more than two complete solar cycles.

\section{DATA AND ANALYSIS}

The sodium data were obtained by the INPE lidar, located at São José dos Campos $\left(23^{\circ} \mathrm{S}, 46^{\circ} \mathrm{W}\right)$. Details of the lidar can be found in Clemesha et al. (2001) and Simonich et al. (1979). Although the equipment has suffered numerous modifications over the years, these should not affect the determination of the centroid height, which is based on a simple and accurate "time of flight" measurement. For further discussion of this point see our earlier papers (Clemesha et al., 1992; Clemesha et al., 1997). The centroid height of the sodium layer undergoes strong diurnal and seasonal variations, and any attempt to extract a long term trend should take these into account. The diurnal variation of the centroid height, shown in Figure 1, taken from Clemesha et al. (1982), shows a maximum excursion of just over $2 \mathrm{~km}$. In our 1992 paper we corrected for this variation by applying an adjustment to the centroid heights according to the time of day. We also computed cen-

troids for the restricted time period 19:00 to 22:00 LT, and showed that the long-term trends obtained by the two methods are similar. In the present work we will limit our analysis to 19:00 to $22: 00 \mathrm{LT}$, during which interval the hourly average centroid height changes by only about $300 \mathrm{~m}$. In view of the fact that many of the centroids used in the analysis refer to the average layer over the entire 19:00 - 22:00 period, and the rest are distributed fairly randomly within this period, any residual effect of the diurnal variation must be very small indeed. Monthly average centroid heights for this time period, from March 1972 to October 2001, are shown in Figure 2. This figure shows considerable month to month dispersion in the centroid heights, but no obvious long-term trend. Note that the heights shown in this paper are referred to the lidar, which is $600 \mathrm{~m}$ above sea level. In our previous papers the heights were referred to sea level.

As mentioned previously, there is a significant seasonal variation in the height of the sodium layer at our location. In Figure 3 we show the average seasonal variation in the centroid height, based on all available 19:00 to 22:00 data. This figure shows a seasonal variation with a total excursion of $1.8 \mathrm{~km}$. This has been taken into account in our trend analysis by subtracting from each data point the appropriate average monthly deviation from the annual mcan. The results are shown in Figure 4. In comparison with Figure 2, it is clear that the removal of the seasonal 
variation has reduced the scatter in height of the data points, but there is still no strong long-term linear trend. A linear regression analysis gives a trend of $93 \pm 53$ meters/decade. An attempt to fit an 11-year oscillation gives negligible amplitude, showing that there is no detectable sunspot cycle component in the centroid height. This new linear trend is much smaller than that observed in our earlier analysis of a shorter data series. The lack of a solar cycle component is not significantly different from our earlier result, since the solar cycle component presented in our 1997 paper was of low statistical significance in any case.

\section{DISCUSSION}

The change in the long-term trend in the centroid height of the atmospheric sodium layer is unexpected. The data up till 1987 appeared to suggest a trend that might be associated with global cooling of the upper atmosphere. After that date there is an abrupt change, with a group of very high centroids between 1988 and 1992. Our data is somewhat sparse in this region and, for this reason, it did not strongly influence the trend reported in our 1997 paper. The centroids from about 1995 on are not greatly different from those observed around 1975 . The greatly reduced trend seen in the extended data set, as compared to the strong trend observed in shorter series, strongly suggests that the trends we reported earlier are not associated with long-term changes in the upper atmosphere.

A complicating factor, which could affect the centroid height of the sodium layer, is the occurrence of sporadic layers. Such layers occur mainly on the topside of the layer, so the presence of a sporadic layer will normally increase the centroid height. Care was taken in analyzing the data to exclude profiles in which sporadic layers were detected. Because the early data generally had a rather poor signal to noise ratio, it is possible that small sporadic layers were not always identified. It is possible that this could have led to a tendency for higher centroids before about 1980 . On the other hand, the pre- 1980 centroids are not greatly different to those seen in recent years. The trend observed from 1972 to 1986 , in fact, mainly stems from the low centroids seen during the later part of this period, from 1980 to 1986.

In our 1997 paper we analyzed the long-term changes which had occurred in the shape of the sodium layer, showing that the decrease in centroid height observed up to 1994 appeared to have resulted from a change in the form of the layer, rather than a simple displacement of the entire layer. On the basis of this we suggested that the observed trend might be the result of a long term change in the phase of the diurnal and semi-diurnal tides, which have been shown to strongly influence the sodium layer (Batista et al., 1985, Clemesha et al., 2002). In view of the fact that the extended data set analyzed herc no longer shows a significant trend in the centroid height, it is worth taking another

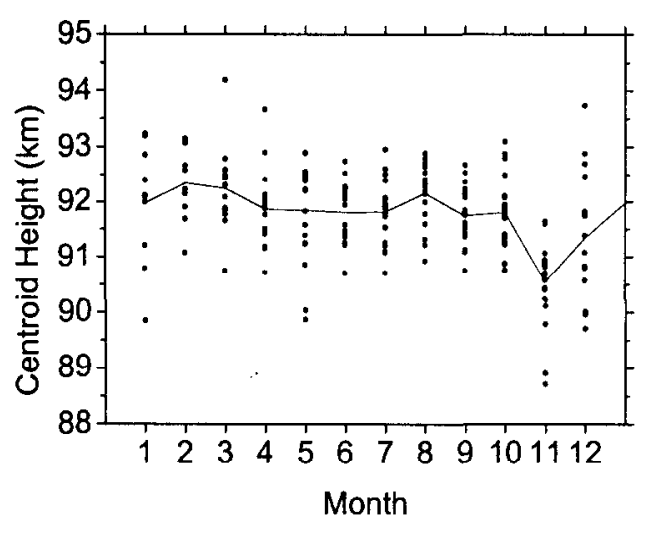

Fig. 3 Seasonal variation in the centroid height of the atmospheric sodium layer.

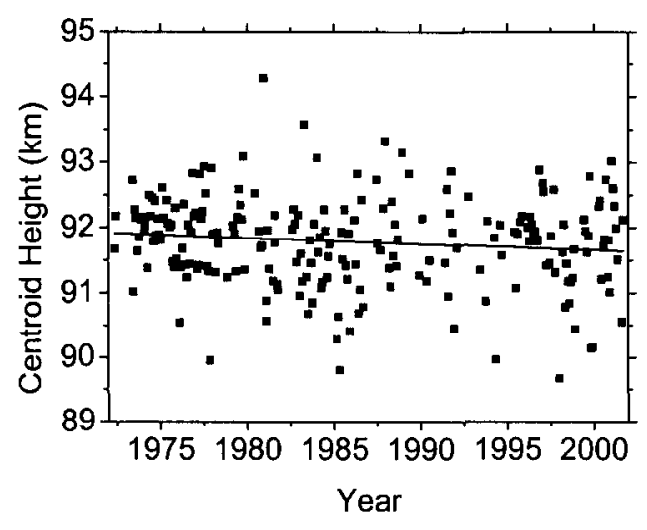

Fig. 4 Monthly average centroids, corrected for seasonal variation, together with linear trend.

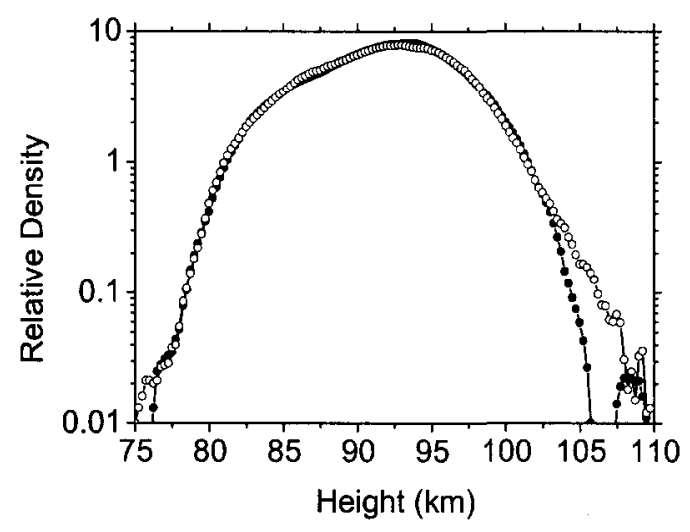

Fig. 5 Average Na profiles for 1972-1986 (closed circles) and 1987-2001 (open circles) respectively. look at the layer shape. To this end we have averaged our normalized monthly mean sodium profiles in two groups: 1972 to 1986 , and 1987 to 2001. Since we do not have data for all months, the averages are effectively centered on July 1979 and June 1995. The results are shown in Figure 5, where the normalized sodium density is plotted on a logarithmic scale as a function of height. Over most of the height range the average profiles are al- 
most identical. Lower densities below $77 \mathrm{~km}$ for the early data could be the result of a small error in the noise subtraction in the data reduction routine used. This would have arisen because for part of that time we were unable to measure the noise for heights above the layer, so the signal between 70 and $75 \mathrm{~km}$ was used as the noise level. The small signal from Rayleigh scattering in this height region would make the noise subtracted slightly greater than it should have been. This effect, however, cannot explain the low sodium concentrations seen above about $103 \mathrm{~km}$ in the 1972 to 1986 average. It should be noted, incidentally, that the sodium density in this region is quite low, and has little influence on the centroid height of the layer. We believe that the increase in density above 103 $\mathrm{km}$ might be related to an apparent increase in the incidence of sporadic sodium layers. Although care was taken to eliminate data in which strong sporadic layers were present, small sporadic layers above $100 \mathrm{~km}$ might well have been included in the analysis. This possibility will be explored elsewhere.

The lack of any significant trend in the centroid height of the atmospheric sodium layer, together with the negligible change in the form of the layer, except at heights above $103 \mathrm{~km}$, suggest that any changes that might have occurred in atmospheric structure in the region of the mesopause over the past 30 years must be very small. We believe it to be particularly significant that the detailed form of the bottomside of the layer, which is believed to be controlled by photochemistry, is almost identical for the two 15 -year average profiles separated by 16 years. Of course, it must not be forgotten that changes in atmospheric structure could influence the sodium chemistry, which might tend to cancel out the direct effect of the subsidence of the isobaric levels. We intend to investigate this possibility in a later paper but, in view of the fact that the heights of the average layers shown in Figure 5 agree to within a small fraction of a $\mathrm{km}$, we believe that our results offer strong evidence for a lack of any major trend in temperature in the region of the mesopause at our location.

\section{CONCLUSION}

The long-term negative trend in the centroid height of the atmospheric sodium layer observed in previous studies does not appear to have been maintained. A new analysis, based on measurements made between 1972 and 2001 , shows a trend of only $-93 \pm 53$ metres/decade. Fifteen-year average profiles of the vertical distribution of sodium, centered on 1979 and 1995 respectively, are almost identical over most of the height range. This new result appears to greatly diminish the possibility that the previously detected trend might be a direct consequence of longterm global cooling of the upper atmosphere.

\section{ACKNOWLEDGMENTS}

We gratefully acknowledge the financial support of the Programa de Núcleos de Excelência - Pronex, the Fundação de Amparo a Pesquisa do Estado de São Paulo - FAPESP and the Conselho Nacional de Desenvolvimento Científico e Tecnológico - CNPq.

\section{REFERENCES}

Aikin, A. C., M. L. Chanin, J. Nash and D. J. Kendig, Temperature trends in the lower mesosphere, Geophys. Res. Lett., 18, 416-419, 1991.

Akmaev, R. A. and V. I. Fomichev, A model estimate of cooling in the mesosphere and lower thermosphere due to the $\mathrm{CO}_{2}$ increase over the last 3-4 decades, Geophys. Res. Lett., 27, 2113-2116, 2000.

Batista, P. P., B. R. Clemesha, D. M. Simonich and V. W. J. H. Kirchhoff, Tidal oscillations in the Atmospheric Sodium Layer, J. Geophys. Res., 90, 3881-3888, 1985.

Bittner, M., D. Offermann and H. H. Graef, Mesopause temperature variability above a midlatitude station in Europe, J. Geophys. Res., 105, 2045-2058, 2000.

Brasseur, G., M. H. Hitchman, S. Walters, M. Dymek, E. Falise and M. Pirre, An interactive chemical dynamical radiative two-dimensional model of the middle atmosphere, J. Geophys. Res., 95, 5639-5656, 1990.

Bremer, J., Ionospheric trends at mid-latitudes as a possible indicator of the atmospheric greenhouse effect, $J . A t$ mos. Sol. Terr. Phys., 54, 1505-1512, 1992.

Clemesha, B. R., D. M. Simonich, P. P. Batista and V. W. J. H. Kirchhoff, The diurnal variation of atmospheric sodium, J. Geophys. Res., 87, 181-186, 1982.

Clemesha, B. R., D. M. Simonich and P. P. Batista, A long-term trend in the height of the atmospheric sodium layer: possible evidence for global change, Geophys. Res. Lett., 19, 457-460, 1992. 
Clemesha, B. R., P. P. Batista and D. M. Simonich, Long-term and solar cycle changes in the atmospheric sodium layer, J. Atmos. Sol. Terr. Phys., 59, 1673-1678, 1997.

Clemesha, B. R., P. P. Batista and D. M. Simonich, Simultaneous measurements of meteor winds and sporadic sodium layers in the $80-110 \mathrm{~km}$ region., Adv. Space Res., 27, 1679-1684, 2001.

Clemesha, B. R., P. P. Batista and D. M. Simonich, Tide-induced oscillations in the atmospheric sodium layer, $J$. Atmos. Sol. Terr. Phys., 64, 1321-1325, 2002.

Dunkerton, T. J., D. P. Delisi and M. P. Baldwin, Middle atmosphere cooling trend in historical rocketsonde data, Geophys. Res. Lett., 25, 3371-3374, 1998.

Garcia, R. S. and S. Solomon, The effect of breaking gravity waves on the dynamics and chemical composition of the mesophere and lower thermosphere, J. Geophys. Res., 90, 3850-3868, 1985.

Golitsyn, G. S., A. I. Semenov, N. N. Shefov, L. M. Fishkova, E. V. Lysenko and S. P. Perov, Long-term temperature trends in the middle and upper atmosphere, Geophys. Res. Lett., 23, 1741-1744, 1996.

Jarvis, M. J., B. Jenkins and G. A. Rodgers, Southern hemisphere observations of a long-term decrease in F region altitude and thermospheric wind providing possible evidence for global thermospheric cooling, $J$. Geophys. Res., 103, 20774-20788, 1998.

Keckhut, P., A. Hauchecorne and M. L. Chanin, Midlatitude long-term variability of the middle atmosphere: Trends and cyclic and episodic changes, J. Geophys. Res., 100, 18, J. Geophys. Res., 100, 18, 1995.

Keckhut, P., J. D. Wild, M. Gelman, A. J. Miler and A. Hauchcome, Investigations on long-term temperature changes in the upper stratosphere using lidar data and NCEP analyses, J. Geophys. Res., 106, 7937-7945, 2001.

Kokin, G. A. and E. V. Lysenko, On temperature trends of the atmosphere from rocket and radiosonde data, J. Atmos. Sol. Terr. Phys., 56, 1035-1040, 1994.

Lubken, F., Nearly zero temperature trend in the polar summer mesosphere, Geophys. Res. Lett., 105, 3603-3606, 2000.

Portmann, R.W., G.E. Thomas, S. Solomon, and R.R. Garcia, The importance of dynamical feedbacks on doubled $\mathrm{CO}_{2}$-induced changes in the thermal structure of the meosphere, Geophys. Res. Lett., 22, 1733-1736, 1995

Roble, R. G. and R. E. Dickinson, How will changes in carbon dioxide and methane modify the mean structure of the mesosphere and thermosphere?, Geophys. Res. Lett., 16, 1441-1444, 1989.

Simonich, D. M., B. R. Clemesha and V. W. J. H. Kirchhoff, The Mesospheric Sodium Layer at 23 S: Nocturnal and Seasonal variations, J. Geophys. Res., 84, 1543-1550, 1979.

Taubenheim, J., G. Entzian and K. Berendorf, Long-term decrease of mesospheric temperature, 1963-1995, inferred from radiowave reflection heights, Adv. Space Res., 20, 2059-2063, 1997.

Email address of Barclay Clemesha: clem@laser.inpe.br

Manuscript received 19 October 2002; accepted 10 March 2003. 